Review

\title{
Papillary Thyroid Cancer: Genetic Alterations and Molecular Biomarker Investigations
}

\author{
Mardiaty Iryani Abdullah' ${ }^{1,5}$, Sarni Mat Junit ${ }^{1}$, Khoon Leong $\mathrm{Ng}^{2}$, Jaime Jacqueline Jayapalan ${ }^{3}$, Barani \\ Karikalan ${ }^{4}$ and Onn Haji Hashim ${ }^{1,3}$ \\ 1. Department of Molecular Medicine, Faculty of Medicine, University of Malaya, 50603 Kuala Lumpur, Malaysia. \\ 2. Department of Surgery, Faculty of Medicine, University of Malaya, 50603 Kuala Lumpur, Malaysia. \\ 3. University of Malaya Centre for Proteomics Research, Faculty of Medicine, University of Malaya, 50603 Kuala Lumpur, Malaysia. \\ 4. Perdana University, Jalan MAEPS Perdana, Serdang 43400, Selangor, Malaysia. \\ 5. Department of Biomedical Science, Kulliyyah of Allied Health Sciences, International Islamic University Malaysia, 25200 Kuantan, Pahang, Malaysia. \\ $\square$ Corresponding author: Professor Dr. Onn Haji Hashim, Department of Molecular Medicine, Faculty of Medicine, University of Malaya, 50603 Kuala Lumpur, \\ Malaysia. Tel.: +603-79674955; Fax: +603-79674957. Email address: onnhashim@um.edu.my \\ (c) Ivyspring International Publisher. This is an open access article distributed under the terms of the Creative Commons Attribution (CC BY-NC) license \\ (https://creativecommons.org/licenses/by-nc/4.0/). See http://ivyspring.com/terms for full terms and conditions.
}

Received: 2018.09.14; Accepted: 2018.12.04; Published: 2019.02.28

\begin{abstract}
Papillary thyroid cancer (PTC) is the most prevalent form of malignancy among all cancers of the thyroid. It is also one of the few cancers with a rapidly increasing incidence. PTC is usually contained within the thyroid gland and generally biologically indolent. Prognosis of the cancer is excellent, with less than $2 \%$ mortality at 5 years. However, more than $25 \%$ of patients with PTC developed a recurrence during a long term follow-up. The present article provides an updated condensed overview of PTC, which focuses mainly on the molecular alterations involved and recent biomarker investigations.
\end{abstract}

Key words: papillary thyroid cancer, molecular alteration, genetic signature, biomarker, diagnostics

\section{Introduction}

Thyroid tumours are now broadly classified as follicle-derived (thyroid epithelial) neoplasms, other epithelial tumours, non-epithelial tumours and secondary tumours based on pathological, clinical and genetic characteristics [1,2]. These tumours can be benign, borderline or malignant, depending on their biological behaviour within the body. The follicular adenoma, hyalinising trabecular tumour, encapsulated follicular-patterned thyroid tumours, papillary thyroid carcinoma (PTC), follicular thyroid carcinoma, Hürthle cell tumour, poorly differentiated thyroid carcinoma, anaplastic thyroid carcinoma and squamous cell carcinoma comprise the major thyroid epithelial neoplasms. Some of the other epithelial tumours found in the thyroid gland include medullary carcinoma, salivary gland-type tumours, mucinous carcinoma and thymic tumours, whilst tumours like paraganglioma, peripheral nerve sheath, vascular, smooth muscle, solitary fibrous and histiocytic tumours, lymphoma and teratoma fall under the non-epithelial tumours of the thyroid (Figure 1).
The well differentiated thyroid cancer such as follicular and papillary carcinomas account for $95 \%$ of all thyroid cancer cases and are generally associated with a good prognosis and/or survival rate when diagnosed early [3,4]. On the other hand, the poorly or undifferentiated anaplastic thyroid carcinoma, albeit a rare cancer, is almost always fatal [5]. Among all cancers of the thyroid, papillary thyroid cancer is the most prevalent form of thyroid malignancy. In the present literature review article, we provide an updated condensed overview which focuses mainly on the molecular alterations involved in tumorigenesis and recent biomarker investigations of PTC.

\section{Papillary Thyroid Cancer}

PTC constitutes approximately $80 \%$ of all thyroid cancer cases [6]. It is also the most prevalent thyroid cancer subtype in countries having iodinesufficient or iodine-excess diets [7]. The incidence of PTC is on the rise [8]. The reasons are unclear but may reflect improvements that contribute to earlier 
detection of the cancer [9]. PTC can occur at any age and has rarely been diagnosed as a congenital tumour [10]. It is usually detected in the third to fifth decades of the patients' life, with the mean age at 40 years. The incidence of PTC increases with age, and women are more frequently affected than men, in ratios of 2:1 to 4:1 [11]. The aetiology of PTC has evoked much interest. The only notable or well-established environmental factor that is related to the progression of PTC is a previous history of radiation exposure [12]. The dropping of the atomic bomb on Hiroshima and Nagasaki at the end of World War II in 1945 and the explosion of the Chernobyl nuclear power station in 1986 confirmed the carcinogenic effect of radiation that led to PTC [13]. Other suggested risk factors include pre-existing benign thyroid disease or having a family history of PTC [14].

\section{Risk of PTC among patients with nodular goitre}

The reported risk of PTC malignancy among patients with benign nodular goitre is not consistent. Earlier studies comparing patients with multiple nodular goitre with those having a single thyroid nodule showed no difference in cancer prevalence [15]. Later studies suggested patients with a solitary thyroid nodule carry a higher risk of thyroid cancer than patients with multiple thyroid nodules [16]. However, these views are no longer tenable as numerous subsequent studies have reported a significant risk of PTC in the patients with multiple thyroid nodules $[17,18]$.

PTC is apparently the most common variety of thyroid malignancy that was incidentally detected in patients with benign thyroid goitre $[19,20]$. The risk of PTC in multinodular goitre is reported to vary from as low as $6 \%$ to as high as $21.2 \%$ [21, 22]. An earlier study by Alevizaki et al. [23] has reported that more than $50 \%$ of PTC cases were incidentally detected in elderly patients operated for pre-existing multinodular goitre. Variation in the frequencies of thyroid cancer in Graves' disease has also been observed, with $0.5 \%$ to $18.7 \%$ of the patients having PTC [24].

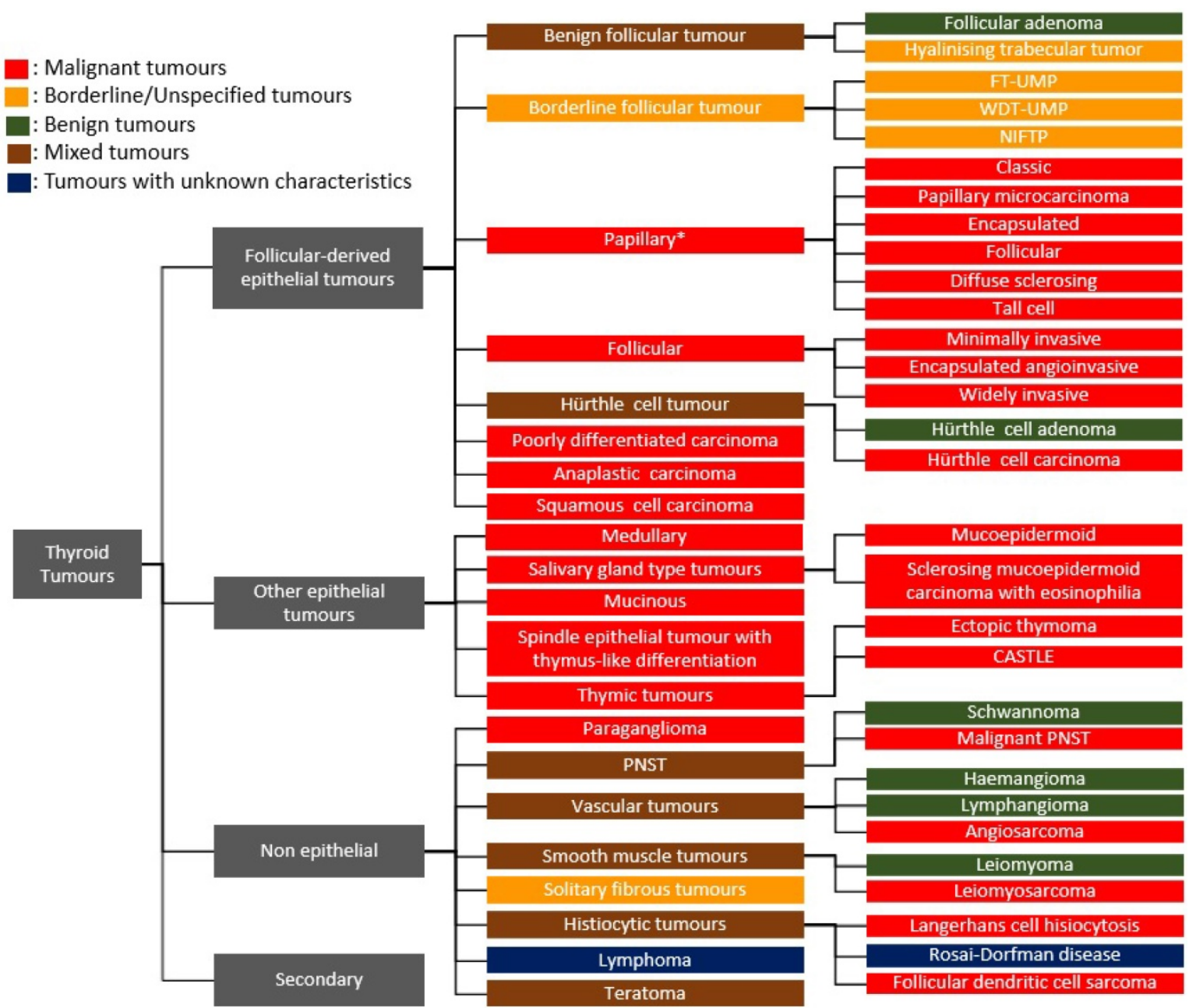

Figure 1. Classification of thyroid tumours. *There are 15 variants of papillary thyroid carcinoma but only the top 6 listed variants are included in this illustration [1]; FT-UMP, Follicular tumour of uncertain malignant potential; WDT-UMP, Well-differentiated tumour of uncertain malignant potential; NIFTP, Non-invasive follicular thyroid neoplasm with papillary nuclear features; CASTLE, Carcinoma showing thymus-like differentiation/intrathyroid epithelial thymoma; PNSTs, Peripheral nerve sheath tumour. 
The demographics of PTC patients are also surrounded by controversies. In an epidemiological survey of 838 patients with multinodular goitre, Luo et al. [25] showed younger age, male sex, fewer nodules and smaller nodule size to be predictors of incidental thyroid cancer. Similar findings of higher risk of malignancy among young males with thyroid nodules have also been independently reported [18]. On the contrary, Wang et al. [17] reported that the female gender and multiple lesions showed higher risk of malignancy, although the risk for smaller nodule size was similarly high. The data of Bombil et al. [21] on 166 cases of PTC patients with concomitant multinodular goitre further adds to the controversy when older age (mean age was 46 years) as well as the female gender were associated with higher risk for malignancy.

\section{Diagnosis of PTC}

Fine needle aspiration and cytology (FNAC) is the method of choice in the diagnosis of PTC [3]. The minimally invasive and rapid procedure involves the use of a narrow gauge needle to obtain a sample of a lesion for microscopic examination. During this procedure, thyroid biopsy specimens are classified by their cytological appearance into benign, suspicious (or indeterminate), or malignant cells [12]. Aspiration smear from PTC may reveal papillary structure, but preoperative diagnosis is mainly based on the recognition of typical nuclear characteristics, such as 'Orphan Annie' nuclei intranuclear pseudoinclusions (due to cytoplasmic invaginations) and nuclear grooves (folds in the nuclear membrane) [11]. The presence of psammoma bodies (calcium salt deposits) in a cervical lymph node provides further evidence of PTC [26].

The accuracy rate of diagnosis with FNAC is about $90 \%$ when correlated with the postoperative diagnosis of surgical specimens [27]. In order to improve the diagnostic yield of FNAC, ultrasonography is usually carried out. The technique is extremely valuable in selecting appropriate nodules to aspirate within a multinodular thyroid or to select a site within a nodule [28]. It can detect presence of nodules that are too small to be palpated, multiple nodules and central or lateral neck lymphadenopathy. Ultrasonography also provides precise dimensions of a nodule for patient's monitoring [29]. Ultrasound features, such as microcalcifications, hypoechoic appearance, increased vascularity, and irregular borders, are useful to differentiate malignancy in PTC patients with benign goitre [30]. Compared to other forms of thyroid malignancy, distant metastasis, usually to the lungs and bones, is less frequent in PTC [31].

\section{Prognosis and Treatment}

Poor prognostic factors of PTC include older age at diagnosis, male gender, large tumour size, and extrathyroidal growth [11]. An aggressive approach in the management and treatment of the disease may render nearly $90 \%$ of the patients cancer-free [32]. Surgery is usually the first-line therapy for PTC. The extent of surgery is dependent on the size of the primary tumour and absence or presence of lymph node metastasis [33]. In cases of malignancy with a diameter of more than $1 \mathrm{~cm}$, total thyroidectomy is usually performed [34]. Oral administered radioiodine is usually recommended subsequent to surgery in all high-risk patients as this will ablate the remaining thyroid cells. A retrospective study performed by Mazzaferri [35] showed lower recurrence rates and improved survival when the remaining thyroid tissue was ablated with radioiodine therapy. For patients whose cancer no longer takes up iodine, tyrosine kinase inhibitors are often prescribed [36].

\section{Recurrence of PTC}

PTC was earlier considered to be of low risk for recurrence, with $99 \%$ survival at 20 years after surgery [37]. However, in a retrospective study of 269 patients, Grogan et al. [38] reported more than $25 \%$ of the subjects had been detected with recurrence of PTC during a long term follow-up. In $11 \%$ of the cases, recurrences from PTC occurred more than 20 years after treatment, hence, leading to the recommendation for a lifelong follow-up of PTC patients. The risk factors identified for PTC recurrence included follicular variant of PTC, older age, cervical lymph node involvement and stage 4 tumors. More recently, Chien et al. [39] identified 676 genes associated with increased risk of PTC recurrence. Upregulation of the genes, which are involved in DNA repair and regulation of the cell cycle, as well as thyroid de-differentiation appeared to have a negative impact on patients' survival.

\section{Molecular alterations in PTC}

Substantial molecular genetic alteration studies performed in the last two decades have given better insights in the understanding of the progression of PTC. PTC is often characterized by RET chromosomal rearrangement, or point mutation of $R A S$ or $B R A F$ proto-oncogenes, all of which are able to trigger the activation of mitogen-activated protein kinase (MAPK) cascade (Figure 2). Mutations of the BRAF, RAS or RET genes are found in nearly $70 \%$ of PTC cases [40]. Genetic events subsequent to the mutations may further lead to numerous different variants of PTC [41]. These variants may be identified via the 
different histopathologic features. The most common are the classical, follicular and tall cell variants. Among the variants of PTC, tall cell and columnar cell variants are biologically more aggressive. Table 1 demonstrates the association of RET, BRAF and RAS gene alterations with the three common PTC variants and their characteristic features [42].

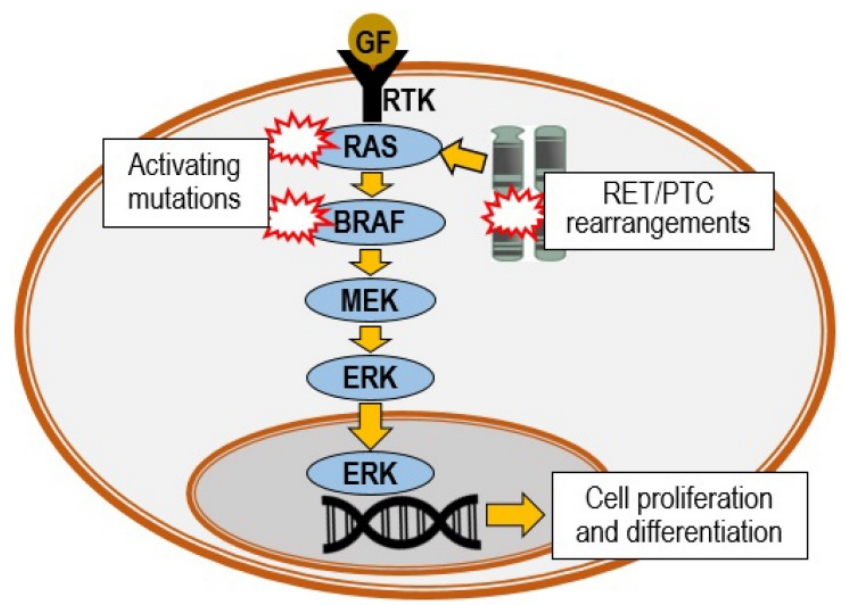

Figure 2. Oncogenic activation of MAPK pathway. The pathway is triggered by binding of growth factor (GF) to a receptor tyrosine kinase (RTK), which activates the RAS, BRAF, MEK and ERK phosphorylation cascade. MEK: MAPK kinase; ERK: extracellular-signal-regulated kinase.

Table 1. Common PTC variants, their characteristic features and associated gene alterations.

\begin{tabular}{llll}
\hline PTC Variant & Classical & Tall cell & Follicular \\
\hline Nuclear features & Pronounced & Pronounced & Less pronounced \\
Psammoma bodies & Common & Common & Rare \\
Lymph node metastasis & Common & Common & Rare \\
Extrathyroidal extension Common & Very common & Rare \\
$\begin{array}{l}\text { Tumour stage at } \\
\text { presentation }\end{array}$ & Early/ & Advance & Intermediate \\
Gene alteration & Advance & & \\
\hline
\end{tabular}

\section{RET rearrangements and PTC}

The RET chromosomal rearrangement was first reported in PTC by Fusco et al. [43]. RET is a proto-oncogene which encodes a plasma membrane bound RET tyrosine kinase receptor for ligands of the glial-derived neurotrophic factor family (GFL) [44]. The RET protein is expressed in the thyroid parafollicular or C cells, whilst, its expression in the thyroid follicular cells remains disputable.

RET/PTC-related carcinogenesis occurs by chromosomal rearrangements, which happens when the C-terminal kinase domain of RET is linked to the promoter and $\mathrm{N}$-terminal domains of unrelated gene(s) [45]. This rearrangement causes RET to be placed under the transcriptional control of its fusion partner gene promoters, and allows the aberrant expression of chimeric protein of the receptor in epithelial follicular thyroid cells [46]. The fusion leaves the tyrosine kinases domain of the RET receptor intact, and enables the RET/PTC chimeric oncoprotein to bind SHC protein adapter which leads to stimulation of the RAS-RAF-MAPK signalling cascade [47]. As a consequence of the rearrangement, the MAPK pathway becomes unrestrained and chronically activated [48]. In addition, the RET/PTC rearrangement has also been suggested to cause deletion of the intracellular juxta membrane domains of the receptor, the extracellular ligand-binding domain and the signal sequence, causing the relocation of the RET/PTC protein into the cytosol as well as preventing it from interacting with its negative regulators [49].

To date, there are at least 13 different forms of RET/PTC rearrangements that have been detected, and these vary according to the different genetic fusion partners [50]. Indeed, these mutations are almost exclusively found in PTC [48]. Among the rearrangements, RET/PTC1 and RET/PTC3 are apparently most common [48, 51], accounting for more than $90 \%$ of all the rearrangements [52]. Both RET/PTC1 and RET/PTC3 oncogenes are created by a paracentric, intrachromosomal inversion of chromosome 10q, in which RET is fused to the activating genes CCDC6 (also known as H4) and NCOA4 (also known as ELE1 or RFG), respectively [49]. At least ten separate genes located on different chromosomes (intrachromosomal rearrangements) have also been shown to arrange with the RET gene, although less frequently [52].

RET/PTC rearrangements occur more frequently in patients less than 45 years old [53]. It is particularly common in paediatric PTC cases and those involving radiation exposures, both from the external beam radiation therapy as well as from nuclear accidents $[48,54]$. In a study of post-Chernobyl paediatric patients, the RET/PTC1 rearrangement was found to be associated with the classical variant of PTC, whilst the RET/PTC3 rearrangement appeared to be more commonly present in solid variant PTC tumours [54]. In addition, RET/PTC rearrangements have also been documented in papillary microcarcinomas at a high frequency, suggesting that they are an early event in the carcinogenesis of PTC [55]. In transgenic mice experiments, the introduction of thyroid-targeted RET/PTC1 oncogene has been shown to induce a PTC-liked morphological changes, particularly in the nuclear cytologic features and presence of local invasion [56].

\section{$B R A F$ oncogene and PTC}

BRAF is part of a signalling pathway known as the RAS/MAPK pathway. It is a member of the RAF 
family of serine-threonine kinases. The activation of BRAF is prompted by binding of RAS to the cell membrane [57]. These kinases are intracellular effectors of the MAPK signalling cascade, which relay the signals downstream and regulate the expression of several genes that are responsible for cell proliferation, differentiation and apoptosis [48].

In thyroid cancer, point mutations, chromosomal rearrangement or small in-frame insertions or deletions can lead to the activation of $B R A F$ [57]. The mutations of $B R A F$ is mutually exclusive with the RET/PTC rearrangement and other common genetic alterations, and is most likely to have an independent oncogenic role as shown in the development of $B R A F$ mutation-initiated PTC in a transgenic mouse studies [58]. The BRAF ${ }^{\mathrm{V} 600 \mathrm{E}}$ is the most commonly reported mutation in patients with PTC [59], while the rarer K601E mutation has been detected in the follicular variant of PTC and benign thyroid adenomas [60].

Earlier studies have associated BRAFV600E mutation with poor prognosis [59, 61]. The high kinase activity of this mutant may drive genetic instability in PTC, facilitating secondary genetic alteration of members of the phosphoinositide 3-kinase-Akt serine/threonine kinase (PI3K-AKT) pathway and mediate its progression to a more aggressive cancer [48]. Since then, there have been many reports, including a few meta-analyses that acknowledged the association of this mutation with high risk clinicopathological features such as lymph node metastases, extrathyroidal invasion, recurrence rate and advanced clinical stage [53, 62, 63]. However, the prognostic value of the BRAFV600E mutation in PTC was made questionable when the statistical data from a large multicentre retrospective study was shown to be insignificant after being adjusted for clinical and clinicopathologic risk factors such as patient age, extrathyroidal invasion, lymph node metastasis, and distant metastasis [64]. Nevertheless, the subsequent data of Xing et al. [65] that was generated from a study of more than 2000 patients from eight different countries again highlighted the potential prognostic value of BRAFV600E mutation in predicting the risk of PTC recurrence. In this case, the association of BRAFV600E mutation with PTC recurrence maintained its significance even after the data was adjusted for the same clinicopathologic risk factors.

\section{RAS oncogenes and PTC}

RAS, which is upstream of BRAF, is a family of GTP-binding proteins that regulate cell growth via the MAPK and PI3K-AKT pathways. Almost one-third of human tumours are presented with RAS mutations [48]. Mutations of RAS were initially reported in thyroid cancer in 1988 [66]. They are found in a wide variety of thyroid tumours including follicular adenomas, follicular carcinomas, poorly differentiated carcinomas, undifferentiated carcinomas as well as papillary carcinomas. Three members of the RAS gene family (HRAS, NRAS and KRAS) have been shown to be mutated in thyroid cancer. The most common RAS mutations were detected in the NRAS gene, followed by HRAS, and least frequently, KRAS [67]. However, later it became clear that the $R A S$ mutations are predominantly related to poorly differentiated thyroid carcinomas and anaplastic thyroid cancers than PTC $[68,69]$, which suggests the role of RAS is more inclined to the progression rather than the initiation of tumours. In a recent report of 199 cases of non-invasive follicular thyroid neoplasm with papillary-like nuclear features, more than half were apparently attributed to RAS mutations [70].

Point mutations in the RAS genes typically occur in codons 12, 13 and 61 . The most frequent mutations lie in codon 61 of NRAS and to a lesser extent in HRAS [45]. RAS mutations have been described to alter GTP-binding affinity or intrinsic GTPase activity [49]. RAS mutants demonstrated distinctive roles in activating the PI3K-AKT and MAPK pathways. In human cancer, whilst the KRAS mutant was detected to be a preferential activator of the MAPK pathway, the NRAS mutant preferentially activates the PI3K-AKT pathway [71]. In PTC, genetic alterations of $R A S$ occur in mutual exclusivity with the BRAF genes [72], suggesting that the RAS mutation is similar to the mutation of $B R A F$, which is capable of affecting PTC independently. The RAS proteins that are translated from the mutant genes cause the constitutive activation of downstream effector pathways that eventually resulted in aberrant cell proliferation and differentiation.

\section{Genetic PTC biomarkers}

Mutations in RET, BRAF and RAS, when analysed simultaneously using DNA microarrays, have been shown to generate distinctive expression profiles that can be used as a genetic signature for their accurate classification [73]. Aside from these mutations, the overall differences in the expression of more than 200 other genes between PTC and normal thyroid tissues when taken together showed strong potential to be utilized as a molecular signature to discriminate the cancer [74]. However, when the data generated from numerous subsequent gene profiling studies were compiled, an overlap between genes regarded as specific to PTC or follicular thyroid carcinoma was frequently detected and became conspicuous (Table 2). One possibility for the "overlap" is that PTC and follicular thyroid carcinoma 
may occur via a common oncogenic pathway. Alternatively, this could have also been attributed to the small sample size of most of the studies, disagreement between pathologists when diagnosing the lesions, and/or the lack of evaluation of other types of thyroid tumours. Nevertheless, some common observation can already be derived from these analyses, such as the upregulated expression of LGALS3, SERPINA1, MET, KRT19, FN1 and TIMP1, as well as downregulated expression of TPO, SLC26A4, DIO1/2 and TFF3 in the well differentiated thyroid carcinomas. However, it is generally clear that more analyses are required before any meaningful conclusions can be made.

\section{MicroRNA PTC biomarkers}

MicroRNAs (miRNAs) are small endogenous non-coding RNAs of approximately 22 nucleotides in length. They have key roles in post-transcriptional regulation of genes by repressing translation and/or degrading their messenger RNA targets in the cytosol, as well as in the alteration of gene expression in the nucleus [75]. At the translational level, it was estimated that miRNAs modulate up to $60 \%$ of the coding genes in the human genome. Because of their ubiquitous role in gene regulation, miRNAs are involved in many intracellular regulatory processes, such as differentiation, proliferation and apoptosis. Hence, dysregulation of miRNAs has been associated with many pathological disorders, including different types of cancer. The altered levels many different miRNAs have also been linked with the metastatic and invasive potential of cancers [76]. Since their early inception studies, there are now more than 2000 human miRNAs that have been annotated in the database and the number is still rapidly increasing [77].

Compared to the genetic analyses, studies on the applications of miRNAs as biomarkers for PTC are relatively more recent. Currently, there have been several reports confirming that PTC is consistently associated with overexpression of specific miRNAs such as mir-146b, miR-221 and miR-222 compared to normal thyroid tissues (Table 3). The expression of these miRNAs was apparently associated with features indicative of tumour aggressiveness such as extrathyroidal extension, recurrence, lymph node or distant metastasis and BRAF ${ }^{\mathrm{V} 600 \mathrm{E}}$ mutation [91, 92]. PTC tumours were also reported to have alterations in the process of miRNA biogenesis. Compared with benign thyroid neoplasms and normal thyroid tissues, the transcription of an RNA endonuclease Dicer, which is involved in the biogenesis and targeting of miRNAs in PTC tissues, was demonstrated to be downregulated. This alteration was also correlated with the same tumour aggressiveness features [93]. miRNAs have also been found in the blood circulation, with their detections in the serum/ plasma, erythrocytes, platelets and nucleated blood cells. The serum/plasma miRNAs are remarkably very stable, and because of that, there have been considerable studies performed to explore the potentials of the extracellular circulating miRNAs for utilization as biomarkers for PTC to distinguish it from normal healthy individuals as well as those with benign thyroid masses (Table 3). Some of these miRNAs also showed strong prognostic utility potentials although there appear to be some minor discrepancies in the reported results of different groups of researchers. For more detailed updates of the diagnostic and prognostic values of miRNAs in PTC as well as all other different types of thyroid tumours, readers are encouraged to read a recent review article by Celano et al. [106].

\section{Proteome-based PTC biomarkers}

Proteomics have been increasingly applied in the search for new diagnostic and prognostic protein biomarkers in cancers [107]. The study usually involves separation of complex mixtures of proteins by two-dimensional electrophoresis (2-DE), differential in-gel electrophoresis (DIGE) or liquid chromatography and identification of resolved proteins by mass spectrometry and database query. Proteomics analyses are usually used in combination with more conventional procedures such as northern and western blotting as well as immunohistochemical staining. For a more quantitative determination of protein amounts, enzyme-linked immunosorbent assay (ELISA) is a method of choice. In PTC, these techniques have been performed to identify proteins that are aberrantly expressed in tissue and serum samples between patients with the cancer and normal healthy individuals or those with benign thyroid goitre (Table 4). In addition, proteomics have also been used to analyse proteins expressed by PTC cell lines, cyst fluid and urine samples.

One of the earliest reported proteomics study of PTC is on the increased expression of prohibitin and ATP synthase D chain in tissue samples of patients relative to the controls [108]. Later, Brown et al. [109] using DIGE and peptide mass fingerprinting, analysed pooled protein extracts from PTC patients' tissues and reported differentially expressed heat shock protein 70 (HSP70), peroxiredoxin (PRDX) and an isoform of $\mathrm{S} 100$ protein (S100A6 protein), compared with matched normal thyroid tissues. Interestingly, overexpression of all the three proteins in PTC tissues was subsequently corroborated by several other independent studies; HSP70 by 
Abdullah et al. [110], PRDX by Giusti et al. [111] and Lee et al. [14], and S100A6 by Sofiadis et al. [112] and Martínez-Aguilar et al. [113]. In addition, overexp- ression of alpha1-antitrypsin (A1AT) in PTC tissue samples was also reported in three separate studies $[14,110,111]$.

Table 2. Gene expression profiling of patients with PTC using microarray.

\begin{tabular}{|c|c|c|c|}
\hline Upregulated genes* & Downregulated genes* & Sample analysed & Reference \\
\hline $\begin{array}{l}\text { CITED1, CHI3L1, ADORA1, SCEL, ODZ1, MET, EPS8, LGALS3, }, \text { KRT19, } \\
\text { CST6, SDC4, DUSP6, TSSC3, TIMP1, SERPINA1, LAMB3, MUC1, } \\
\text { PROS1, SFPTB }\end{array}$ & $\begin{array}{l}\text { MT1G, } \underline{D I O 1}, \underline{D I O 2}, \underline{T P O}, B C L 2 ; \text { DUSP1, } \\
\text { FOSB, CRABP1 }\end{array}$ & 8 PTCs and matched normal & [74] \\
\hline MET MMP11, PLAB, FN1, HIF1, HLA-DBP1, AHR, $\underline{\text { TIMP1 }}$ & $\begin{array}{l}\text { GADD153, PKD1, CYR61, HBA1, } \\
\text { DPC4/SMAD4, DLG3 }\end{array}$ & 18 PTCs and 3 normal & [78] \\
\hline 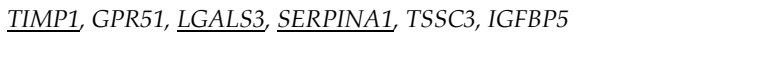 & $\underline{T F F 3}$, CRABP1, FCGBP, $\underline{T P O}, I D 1, R B 1$ & $\begin{array}{l}8 \text { PTCs, } 6 \text { NGs, and matched } \\
\text { normal }\end{array}$ & [79] \\
\hline $\begin{array}{l}\text { TACSTD2, AMM, AHR, MKP2, FN1, KRT19, HGFR, LGALS3, HER3, } \\
\text { TIMP, Cathepsin C, TGF alpha, SERPINA1, SYND4, EPS8, NRP2, } \\
\text { ALDH4, Dystrophin, COL8A1, HLA-DQ beta }\end{array}$ & & 14 PTCs and 21 benign lesions & {$[80]$} \\
\hline $\begin{array}{l}\text { CCND1, FGF, VEGFB, PDGFA, BMP5, TGRB, HGFL, FGFR2, IGF1, } \\
\text { MPK, CDH1, CHD3 }\end{array}$ & $\underline{T P O}$, NIS, TSHR & 7 PTCs and matched normal & [81] \\
\hline $\begin{array}{l}\text { ZBTB3, GFER, GPC1, TMSB4X, BMP7, Cathepsin H, SERPINA1, CNN3, } \\
\text { MET, LGALS3, CEACAM7, TGFB1I4, HLA-B, ADAM19, KCNAB }\end{array}$ & PAX8, TG & 16 PTCs, 13 FTCs, and 17 normal & [82] \\
\hline 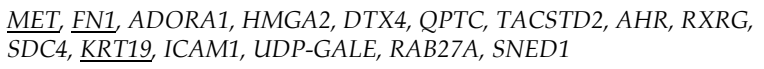 & $\begin{array}{l}\text { DIO1, BCL2, TPO, MT1G, EMID1, } \\
\text { CDH16, ITPR1, HGD, CA4, ID3 }\end{array}$ & $\begin{array}{l}57 \text { PTCs, } 61 \text { benign lesions, and } \\
62 \text { normal }\end{array}$ & [83] \\
\hline 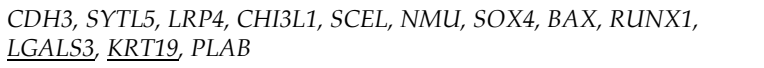 & & 9 PTCs and 11 normal & {$[84]$} \\
\hline CST6, CXCL14, BCAN, DHRS3, LGALS3, SLC34A2, NMU, NRGN & & 28 PTCs, 17 FTCs and 14 normal & [85] \\
\hline SLC34A2, TM7SF4, COMP, KLK7, KCNJ2, SERPINA1 & $\begin{array}{l}\text { FOXA2, SLC4A4, LYVE-1, OTOS, } \\
\text { TFCP2L1 }\end{array}$ & 35 PTCs and matched normal & [86] \\
\hline SERPINA1, KRT19, CITED1, CDH3, DPP4, TIMP1, PROS1, LAMB3 & $\underline{T F F 3}$ & PTCs and NG & [87] \\
\hline $\begin{array}{l}\text { CDH3, NGEF, PROS1, MET, CTXN1, SDC4, HPN, NRCAM, PSD3, } \\
\text { GALE, SCEL }\end{array}$ & $\overline{\text { LIFR }}, M A F B, B M P 2, A N K R D 37$ & 19 PTCs and 7 normal & {$[88]$} \\
\hline \multirow{3}{*}{$\underline{M E T}, \underline{\text { SERPINA1}}, \underline{\text { LGALS3 }}, \underline{\text { FN1 }}$, LAMB3, COL13A1 } & CUX2, TFF3, FOXA2 & 7 PTCs and 7 normal & [6] \\
\hline & TNFRSF11B & 16 PTCs and matched normal & [89] \\
\hline & CXCL12 & 3 PTCs and matched normal & [90] \\
\hline
\end{tabular}

${ }^{*}$ Commonly expressed genes are shown in bold and underlined. FTC: follicular thyroid carcinoma; PTC: papillary thyroid carcinoma; NG: nodular goitre.

Table 3. Dysregulated tissue and circulating miRNA in PTC.

\begin{tabular}{|c|c|c|c|}
\hline Sample & miRNA & Oncogenic alteration & Reference \\
\hline \multirow[t]{10}{*}{ Tissue (PTC vs Normal) } & $\uparrow 146 \mathrm{~b}, 221,222$ & n.d & [94] \\
\hline & $\uparrow 181 \mathrm{~b}, 221,222$ & n.d. & [95] \\
\hline & $\uparrow 146 b, 221,222 ; \downarrow 187$ & BRAFV600E & [40] \\
\hline & $\uparrow 187$ & RET/PTC, RAS & \\
\hline & $\uparrow 21,203$ & BRAFV600E & [92] \\
\hline & $\uparrow 451$ & n.d. & [17] \\
\hline & $\downarrow 137$ & n.d. & [96] \\
\hline & $\downarrow 451 \mathrm{a}$ & n.d. & [97] \\
\hline & $\uparrow 146 \mathrm{~b}$ & BRAFV600E & [91] \\
\hline & $\begin{array}{l}\uparrow 146 b-5 p, 146 b-3 p, 221-3 p, 222-5 p, 222-3 p \\
\downarrow 1179,486-5 p, 204-5 p, 7-2-3 p, 144-5 p, 140-3 p\end{array}$ & n.d. & [98] \\
\hline \multirow[t]{3}{*}{ Serum/Plasma (PTC vs Normal) } & $\uparrow$ let-7e, $151-5 \mathrm{p}, 222$ & n.d. & [99] \\
\hline & $\uparrow 146 b, 222$ & n.d. & [100] \\
\hline & $\uparrow 190 ; \downarrow 95$ & n.d. & [101] \\
\hline \multirow[t]{5}{*}{ Serum/Plasma (PTC vs BTN) } & $\uparrow$ let-7e, 151-5p, 222 & n.d. & [99] \\
\hline & $\uparrow 25-3 p, 451 a$ & n.d. & [102] \\
\hline & $\begin{array}{l}\uparrow \text { let7b-5p, 10a-5p; } \\
\downarrow 146 a-5 p, 199 \mathrm{~b}-3 \mathrm{p}\end{array}$ & n.d. & [103] \\
\hline & $\uparrow 9-3 p, 124-3 p$ & n.d. & [104] \\
\hline & $\downarrow 151-5 p, 221,222$ & n.d. & [105] \\
\hline
\end{tabular}

$\uparrow$ : overexpressed; $\downarrow$ : underexpressed; n.d.: not determined; BTN: benign thyroid nodules.

Table 4. Aberrantly expressed proteins in PTC.

\begin{tabular}{lllll}
\hline Comparison & Samples & Aberrant Proteins & Techniques & References \\
\hline PTC, FTC, benign, and normal tissues & Tissue & $\uparrow$ CTSB, ATP5H, and PHB & 2-DE & {$[107]$} \\
PTC and normal tissues & Tissue & $\uparrow$ S100A6, PRDX, and & 2-D DIGE, MALDI-TOF MS, and IHC [109] & \\
& & HSP70 & & \\
PTC and benign tissues & Tissue and FNAC & $\uparrow$ LGALS1 and LGALS3 & 2-DE, LC-MS, and IHC & {$[116]$} \\
FV-PTC, TCV-PTC and benign tissues & FNAC & $\uparrow$ TTR, FLC, A1AT, & 2-DE, MALDI-TOF MS, and Western & {$[111]$} \\
\hline
\end{tabular}




\begin{tabular}{|c|c|c|c|c|}
\hline Comparison & Samples & Aberrant Proteins & Techniques & References \\
\hline & & $\begin{array}{l}\text { GAPDH, LDH-B, APOA1, } \\
\text { ANXA1, DJ-1 protein, } \\
\text { cofilin-1, and PRDX1 }\end{array}$ & blotting & \\
\hline PTC and healthy controls & Serum & $\begin{array}{l}\uparrow \mathrm{HAP} \alpha 1 ; \downarrow \text { APOC } 1 \text { and } \\
\text { APOC3 }\end{array}$ & $\begin{array}{l}\text { SELDI-TOF-MS, LC-MS-MS and } \\
\text { ProteinChip immunoassays }\end{array}$ & [114] \\
\hline PTC and normal tissues & Tissue & $\downarrow$ ANXA3 & $\begin{array}{l}\text { 2-DE, MALDI-TOF-MS, Western } \\
\text { blotting, Northern blotting and IHC }\end{array}$ & [117] \\
\hline PTC, FTC, and normal tissues & Tissue & $\uparrow \mathrm{S} 100 \mathrm{~A} 6$ & $\begin{array}{l}\text { SELDI-TOF-MS, Western blotting and } \\
\text { IHC }\end{array}$ & [112] \\
\hline PTC and other nodular thyroid lesions & Tissue & $\uparrow \mathrm{CaT12}$ & ELISA, IHC, LC-MS-MS & [118] \\
\hline PTC and normal tissues & Tissue & $\begin{array}{l}\uparrow \text { enolase } 1 \text {, TPI, cathepsin } \\
\text { D, annexin A2, cofilin 1, } \\
\text { PCNA, copine } 1 \text {, HSP27 }\end{array}$ & 2DE, LC-MS-MS, Western Blotting, & [4] \\
\hline PTC and normal tissue & Tissue & $\uparrow$ ribosomal protein P2 & IMS, MALDI-TOF, LC-ESI-MS/MS & [119] \\
\hline PTC and benign tissues & Cyst fluid & $\uparrow$ CK19 and S100A13 & $\begin{array}{l}\text { LC-MS/MS, Western blotting, IHC, } \\
\text { and ELISA }\end{array}$ & [120] \\
\hline PTC and benign tissues & Tissue & $\begin{array}{l}\uparrow 26 \text { proteins including } \\
\text { PRDX and SERPINA1 }\end{array}$ & 2-DE, LC-MS/MS Q-TOF & [14] \\
\hline $\begin{array}{l}\text { PTC patients with and without benign } \\
\text { background }\end{array}$ & Tissue and Serum & $\begin{array}{l}\text { Tissue: } \uparrow \text { A1AT, HSP70, } \downarrow \\
\text { A1AT, PDI and UBE2N } \\
\text { Serum: } \uparrow \text { A1AT, A1B, } \\
\text { APOA4 and AHSG }\end{array}$ & 2-DE, LC-MS/MS Q-TOF, and ELISA & [110] \\
\hline PTC, FTC and normal tissues & Tissue & $\begin{array}{l}\uparrow \text { ANXA1, TMSB10, GAL3, } \\
\text { CK19, ICAM1, GALE, } \\
\text { CRABP1, FN1, and S100A6; } \\
\downarrow \text { TPO and DEHAL1 }\end{array}$ & $\begin{array}{l}\text { SWATH-MS, iTRAQ-MS, and } \\
\text { Western blotting }\end{array}$ & [113] \\
\hline $\begin{array}{l}\text { PTC GLAG-66-CXCR7-1 cell line and } \\
\text { control GLAG-66-1 cells }\end{array}$ & Cell lines & $\uparrow$ AHNAK2 and TAGLN2 & $\begin{array}{l}\text { iTRAQ-coupled 2D LC-MS/MS, and } \\
\text { Western blotting }\end{array}$ & [121] \\
\hline Patients with PTC/BTG: controls & Urine & $\begin{array}{l}\text { PTC: } \uparrow \text { Gelsolin } \\
\text { BTG: } \downarrow \text { Osteopontin }\end{array}$ & $\begin{array}{l}\text { iTRAQ-coupled 2D LC-MS/MS, and } \\
\text { Western blotting }\end{array}$ & [115] \\
\hline
\end{tabular}

$\uparrow$ : overexpressed; $\downarrow$ : underexpressed; PTC: papillary thyroid carcinoma; FTC: follicular thyroid carcinoma; BTG: benign thyroid goitre; cPTC: classical variant PTC; TCV: tall cell variant.

Currently, the proteomics analysis of serum samples of patients with PTC is apparently restricted to only two reports. Using SELDI-TOF MS, which analyses only low molecular weight polypeptides, Fan et al. [114] reported different altered levels of serum haptoglobin alpha1 chain, and apolipoproteins C1 and C3 in PTC patients, whilst Abdullah et al. [110] reported that PTC patients with history of benign thyroid goitre showed altered serum levels of A1AT, alpha 1-beta glycoprotein, apolipoprotein A-IV and alpha 2-HS glycoprotein relative to those without the history. The field of quantitative proteomics has progressed rapidly with the development of new state-of-the-art techniques such as iTRAQ (isobaric tag for relative and absolute quantitation) and SWATH (sequential window acquisition of all theoretical spectra) mass spectrometry. Already these techniques have been used to identify proteins with altered abundance in tissue and urine samples of patients with PTC $[113,115]$, which hopefully can be used to discriminate the cancer from follicular thyroid cancer and/or non-cancer.

\section{Conclusion}

Existing molecular evidence suggests that PTC, the most prevalent form of thyroid malignancy, is etiopathogenically complex and requires further in-depth investigations. The presently limited genomic, miRNA and proteomic biomarker discovery analyses performed in PTC, when taken together, also show the need for more future studies so that the findings can eventually be translated into useful clinical applications in the diagnosis and management of the cancer that is rapidly increasing in incidence and recurrence.

\section{Acknowledgement}

This work was supported by the FG017-17AFR and BR002-2017 grants from the University of Malaya.

\section{Competing Interests}

The authors have declared that no competing interest exists.

\section{References}

1. Lam AK. Pathology of Endocrine Tumors Update: World Health Organization New Classification 2017 - Other Thyroid Tumors. AJSP: Reviews \& Reports. 2017; 22: 209-16.

2. Bychkov A. World Health Organization (WHO) classification. http://www.pathologyoutlines.com/topic/thyroidwho.html. Accessed September 11th, 2018.

3. Maia FFR, Zantut-Wittmann DE. Thyroid nodule management: Clinical, ultrasound and cytopathological parameters for predicting malignancy. Clinics. 2012; 67: 945-54.

4. Paricharttanakul NM, Saharat K, Chokchaichamnankit D, Punyarit P, Srisomsap C, Svasti J. Unveiling a novel biomarker panel for diagnosis and classification of well-differentiated thyroid carcinomas. Oncol Rep. 2016; 35: 2286-96.

5. Liu TR, Xiao ZW, Xu HN, Long Z, Wei FQ, Zhuang SM, et al. Treatment and prognosis of anaplastic thyroid carcinoma: A clinical study of 50 cases. PloS One. 2016; 11: e0164840.

6. Zhu X, Yao J, Tian W. Microarray technology to investigate genes associated with papillary thyroid carcinoma. Mol Med Rep. 2015; 11: 3729-33. 
7. Al-Salamah SM, Khalid K, Bismar HA. Incidence of differentiated cancer in nodular goiter. Saudi Med J. 2002; 23: 947-52.

8. Raposo L, Morais S, Oliveira MJ, Marques AP, Jose Bento M, Lunet N. Trends in thyroid cancer incidence and mortality in Portugal. Eur J Cancer Prev. 2017; 26: 135-43.

9. Davies L, Welch HG. Increasing incidence of thyroid cancer in the United States, 1973-2002. JAMA. 2006; 295: 2164-7.

10. Todaro M BS, Mannino E, Stassi G. Role of IL-4 and IL-10 cytokines in the pathogenic mechanism of thyroid cancer. In: Milton CA, editor. Trends in Thyroid Cancer Research New York: Nova Science Publishers Inc.; 2007.

11. LiVolsi VA. Papillary thyroid carcinoma: An update. Mod Pathol. 2011; 24 Suppl 2: S1-9.

12. Constantinides V, Pallazzo F. Goitre and thyroid cancer. Medicine. 2013; 41: 546-50.

13. Iglesias ML, Schmidt A, Ghuzlan AA, Lacroix L, Vathaire F, Chevillard $S$, et al. Radiation exposure and thyroid cancer: A review. Arch Endocrinol Metab. 2017; 61: 180-7.

14. Lee CC AM, Junit SM, Ng KL, Wong SY, Ramli NSF, Hashim OH. Malignant transformation of benign thyroid nodule is caused by prolonged $\mathrm{H} 2 \mathrm{O} 2$ insult that interfered with the STAT3 pathway? Int J Clin Exp Med 2016; 9: 18601-17.

15. Belfiore A, La Rosa GL, La Porta GA, Giuffrida D, Milazzo G, Lupo L, et al. Cancer risk in patients with cold thyroid nodules: relevance of iodine intake, sex, age, and multinodularity. Am J Med. 1992; 93: 363-9.

16. Barroeta JE, Wang H, Shiina N, Gupta PK, Livolsi VA, Baloch ZW. Is fine-needle aspiration (FNA) of multiple thyroid nodules justified? Endocr Pathol. 2006; 17: 61-5.

17. Wang SF, Zhao WH, Wang WB, Teng XD, Teng LS, Ma ZM. Clinical features and prognosis of patients with benign thyroid disease accompanied by an incidental papillary carcinoma. Asian Pac J Cancer Prev. 2013; 14: 707-11

18. Smith JJ, Chen X, Schneider DF, Broome JT, Sippel RS, Chen H, et al. Cancer after thyroidectomy: A multi-institutional experience with 1,523 patients. J Am Coll Surg. 2013; 216: 571-7.

19. Lin JS, Aiello Bowles EJ, Williams SB, Morrison CC. Screening for thyroid cancer: A systematic evidence review for the US Preventive Services Task Force. Rockville (MD): Agency for Healthcare Research and Quality (US); 2017.

20. Rahman MM AM, Karim MA, Arafat MS, Hanif M, Tarafder KH. Frequency of malignancy in multinodular goitre. Bangladesh J Otorhinolaryngol 2015; 20: 75-9.

21. Bombil I, Bentley A, Kruger D, Luvhengo TE. Incidental cancer in multinodular goitre post thyroidectomy. S Afr J Surg. 2014; 52: 5-9.

22. Ullah I HM, Ahmad N, Muahammad G, Gandapur S. Incidence of thyroid malignancy in multinodular goiter. J Med Sci 2014; 22: 164-5.

23. Alevizaki M, Papageorgiou G, Rentziou G, Saltiki K, Marafelia P, Loukari $\mathrm{E}$, et al. Increasing prevalence of papillary thyroid carcinoma in recent years in Greece: The majority are incidental. Thyroid. 2009; 19: 749-54.

24. Pazaitou-Panayiotou K, Michalakis K, Paschke R. Thyroid cancer in patients with hyperthyroidism. Horm Metab Res. 2012; 44: 255-62.

25. Luo J, McManus C, Chen H, Sippel RS. Are there predictors of malignancy in patients with multinodular goiter? J Surg Res. 2012; 174: 207-10

26. Hunt JL, Barnes EL. Non-tumor-associated psammoma bodies in the thyroid. Am J Clin Pathol. 2003; 119: 90-4.

27. Neki N KH. Solitary thyroid nodule - An insight. JIACM 2006; 7: 328-33.

28. Papini E, Guglielmi R, Bianchini A, Crescenzi A, Taccogna S, Nardi F, et al. Risk of malignancy in nonpalpable thyroid nodules: Predictive value of ultrasound and color-doppler features. J Clin Endocrinol Metab. 2002; 87: 1941-6.

29. Bomeli SR, LeBeau SO, Ferris RL. Evaluation of a thyroid nodule. Otolaryngol Clin North Am. 2010; 43: 229-38.

30. Lin J-D. Thyroid cancer in thyroid nodules diagnosed using ultrasonography and fine needle aspiration cytology. J Med Ultrasound. 2010; 18: 91-104.

31. Zeiger MA, Dackiw APB. Follicular thyroid lesions, elements that affect both diagnosis and prognosis. J Surg Oncol 2005; 89: 108-13.

32. Mazzaferri EL, Massoll N. Management of papillary and follicular (differentiated) thyroid cancer: New paradigms using recombinant human thyrotropin. Endocr Relat Cancer. 2002; 9: 227-47.

33. diMarco A, Palazzo F. Goitre and thyroid cancer. Medicine. 2017; 45: 517-22.

34. Mackenzie EJ, Mortimer RH. 6: Thyroid nodules and thyroid cancer. Med J Aust. 2004; 180: 242-7.

35. Mazzaferri EL. An overview of the management of papillary and follicular thyroid carcinoma. Thyroid. 1999; 9: 421-7.
36. Nguyen QT, Lee EJ, Huang MG, Park YI, Khullar A, Plodkowski RA. Diagnosis and treatment of patients with thyroid cancer. Am Health Drug Benefits. 2015; 8: 30-40.

37. Kakudo K, Tang W, Ito Y, Mori I, Nakamura Y, Miyauchi A. Papillary carcinoma of the thyroid in Japan: Subclassification of common type and identification of low risk group. J Clin Pathol. 2004; 57: 1041-6.

38. Grogan RH, Kaplan SP, Cao H, Weiss RE, Degroot LJ, Simon CA, et al. A study of recurrence and death from papillary thyroid cancer with 27 years of median follow-up. Surgery. 2013; 154: 1436-46; discussion 46-7.

39. Chien MN, Yang PS, Lee JJ, Wang TY, Hsu YC, Cheng SP. Recurrence-associated genes in papillary thyroid cancer: An analysis of data from the cancer genome atlas. Surgery. 2017; 161: 1642-50.

40. Nikiforova MN, Tseng GC, Steward D, Diorio D, Nikiforov YE. MicroRNA expression profiling of thyroid tumors: Biological significance and diagnostic utility. J Clin Endocrinol Metab. 2008; 93: 1600-8.

41. Lloyd RV, Buehler D, Khanafshar E. Papillary thyroid carcinoma variants. Head Neck Pathol. 2011; 5: 51-6.

42. Adeniran AJ, Zhu Z, Gandhi M, Steward DL, Fidler JP, Giordano TJ, et al. Correlation between genetic alterations and microscopic features, clinical manifestations, and prognostic characteristics of thyroid papillary carcinomas. Am J Surg Pathol. 2006; 30: 216-22.

43. Fusco A, Grieco M, Santoro M, Berlingieri MT, Pilotti S, Pierotti MA, et al. A new oncogene in human thyroid papillary carcinomas and their lymph-nodal metastases. Nature. 1987; 328: 170.

44. Treanor JJ, Goodman L, de Sauvage F, Stone DM, Poulsen KT, Beck CD, et al. Characterization of a multicomponent receptor for GDNF. Nature. 1996; 382: 80-3.

45. Fagin JA, Mitsiades N. Molecular pathology of thyroid cancer: Diagnostic and clinical implications. Best Pract Res Clin Endocrinol Metab. 2008; 22: 955-69.

46. Nikiforov YE. RET/PTC rearrangement in thyroid tumors. Endocr Pathol. 2002; 13: 3-16.

47. Knauf JA, Kuroda H, Basu S, Fagin JA. RET/PTC-induced dedifferentiation of thyroid cells is mediated through Y1062 signaling through SHC-RAS-MAP kinase. Oncogene. 2003; 22: 4406-12.

48. Grogan RH, Mitmaker EJ, Clark OH. The evolution of biomarkers in thyroid cancer-from mass screening to a personalized biosignature. Cancers (Basel). 2010; 2: 885-912.

49. Cassol CA, Asa SL. Molecular pathology of thyroid cancer. Diagn Histopathol. 17: 124-39.

50. Romei C, Elisei R. RET/PTC translocations and clinico-pathological features in human papillary thyroid carcinoma. Front Endocrinol (Lausanne). 2012; 3: 54.

51. Kitamura Y, Minobe K, Nakata T, Shimizu K, Tanaka S, Fujimori M, et al. RET/PTC3 is the most frequent form of gene rearrangement in papillary thyroid carcinomas in Japan. J Hum Genet. 1999; 44: 96-102.

52. Greco A MC, Borrello MG, Pierotti MA. Thyroid cancer In: Dellaire G BJ, Arceci RJ editor. Cancer genomics Boston Academic Press; 2014. p. 265-80

53. Ming J, Liu Z, Zeng W, Maimaiti Y, Guo Y, Nie X, et al. Association between BRAF and RAS mutations, and RET rearrangements and the clinical features of papillary thyroid cancer. Int J Clin Exp Pathol. 2015; 8: 15155-62.

54. Nikiforov YE, Rowland JM, Bove KE, Monforte-Munoz H, Fagin JA. Distinct pattern of RET oncogene rearrangements in morphological variants of radiation-induced and sporadic thyroid papillary carcinomas in children. Cancer Res. 1997; 57: 1690-4.

55. Sugg SL, Zheng L, Rosen IB, Freeman JL, Ezzat S, Asa SL. ret/PTC-1, -2, and -3 oncogene rearrangements in human thyroid carcinomas: Implications for metastatic potential? J Clin Endocrinol Metab. 1996; 81: 3360-5.

56. Jhiang SM, Sagartz JE, Tong Q, Parker-Thornburg J, Capen CC, Cho JY, et al. Targeted expression of the ret/PTC1 oncogene induces papillary thyroid carcinomas. Endocrinology. 1996; 137: 375-8.

57. Nikiforov YE, Nikiforova MN. Molecular genetics and diagnosis of thyroid cancer. Nat Rev Endocrinol. 2011; 7: 569-80.

58. Rusinek D, Swierniak M, Chmielik E, Kowal M, Kowalska M, Cyplinska $\mathrm{R}$, et al. BRAFV600E-associated gene expression profile: Early changes in the transcriptome, based on a transgenic mouse model of papillary thyroid carcinoma. PLoS ONE. 2015; 10: e0143688.

59. Xing M. BRAF mutation in thyroid cancer. Endocr Relat Cancer. 2005; 12 : $245-62$.

60. Trovisco V, Vieira de Castro I, Soares P, Maximo V, Silva P, Magalhaes J, et al. BRAF mutations are associated with some histological types of papillary thyroid carcinoma. J Pathol. 2004; 202: 247-51.

61. Lee JH, Lee ES, Kim YS. Clinicopathologic significance of BRAF V600E mutation in papillary carcinomas of the thyroid: A meta-analysis. Cancer. 2007; 110: 38-46. 
62. Li C, Lee KC, Schneider EB, Zeiger MA. BRAF V600E mutation and its association with clinicopathological features of papillary thyroid cancer: A meta-analysis. J Clin Endocrinol Metab. 2012; 97: 4559-70.

63. Chakraborty A, Narkar A, Mukhopadhyaya R, Kane S, D'Cruz A, Rajan MG. BRAF V600E mutation in papillary thyroid carcinoma: Significant association with node metastases and extra thyroidal invasion. Endocr Pathol. 2012; 23: 83-93.

64. Cappola AR, Mandel SJ. Molecular testing in thyroid cancer: BRAF mutation status and mortality. JAMA. 2013; 309: 1529-30.

65. Xing M, Alzahrani AS, Carson KA, Shong YK, Kim TY, Viola D, et al. Association between BRAF V600E mutation and recurrence of papillary thyroid cancer. J Clin Oncol. 2015; 33: 42-50.

66. Lemoine NR, Mayall ES, Wyllie FS, Farr CJ, Hughes D, Padua RA, et al. Activated RAS oncogenes in human thyroid cancers. Cancer Res. 1988; 48: 4459-63.

67. Moura M, Cavaco B, Leite V. RAS proto-oncogene in medullary thyroid carcinoma. Endocrine-Related Cancer 2015; 22: R235-52.

68. Lloyd RV, Erickson LA, Casey MB, Lam KY, Lohse CM, Asa SL, et al. Observer variation in the diagnosis of follicular variant of papillary thyroid carcinoma. Am J Surg Pathol. 2004; 28: 1336-40.

69. Elsheikh TM, Asa SL, Chan JK, DeLellis RA, Heffess CS, LiVolsi VA, et al. Interobserver and intraobserver variation among experts in the diagnosis of thyroid follicular lesions with borderline nuclear features of papillary carcinoma. Am J Clin Pathol. 2008; 130: 736-44.

70. Paulson VA, Shivdasani P, Angell TE, Cibas ES, Krane JF, Lindeman NI, et al. Noninvasive follicular thyroid neoplasm with papillary-like nuclear features accounts for more than half of "carcinomas" harboring RAS mutations. Thyroid. 2017; 27: 506-11.

71. Haigis KM, Kendall KR, Wang Y, Cheung A, Haigis MC, Glickman JN, et al. Differential effects of oncogenic K-Ras and N-Ras on proliferation, differentiation and tumor progression in the colon. Nat Genet. 2008; 40: $600-8$.

72. Brehar AC, Brehar FM, Bulgar AC, Dumitrache C. Genetic and epigenetic alterations in differentiated thyroid carcinoma. J Med Life. 2013; 6: 403-8.

73. Giordano TJ, Kuick R, Thomas DG, Misek DE, Vinco M, Sanders D, et al. Molecular classification of papillary thyroid carcinoma: Distinct BRAF, RAS, and RET/PTC mutation-specific gene expression profiles discovered by DNA microarray analysis. Oncogene. 2005; 24: 6646-56.

74. Huang Y, Prasad M, Lemon WJ, Hampel H, Wright FA, Kornacker K, et al. Gene expression in papillary thyroid carcinoma reveals highly consistent profiles. Proc Natl Acad Sci U S A. 2001; 98: 15044-9.

75. Catalanotto C, Cogoni C, Zardo G. Microrna in control of gene expression: An overview of nuclear functions. Int J Mol Sci. 2016; 17.

76. de la Chapelle A, Jazdzewski K. MicroRNAs in thyroid cancer. J Clin Endocrinol Metab. 2011; 96: 3326-36.

77. Londin E, Loher P, Telonis AG, Quann K, Clark P, Jing Y, et al. Analysis of 13 cell types reveals evidence for the expression of numerous novel primate- and tissue-specific microRNAs. Proc Natl Acad Sci U S A. 2015; 112: E1106-15.

78. Wasenius VM, Hemmer S, Kettunen E, Knuutila S, Franssila K, Joensuu H. Hepatocyte growth factor receptor, matrix metalloproteinase-11, tissue inhibitor of metalloproteinase-1, and fibronectin are up-regulated in papillary thyroid carcinoma: A cDNA and tissue microarray study. Clin Cancer Res. 2003; 9: 68-75.

79. Hawthorn L, Stein L, Varma R, Wiseman S, Loree T, Tan D. TIMP1 and SERPIN-A overexpression and TFF3 and CRABP1 underexpression as biomarkers for papillary thyroid carcinoma. Head Neck. 2004; 26: 1069-83.

80. Finley DJ, Arora N, Zhu B, Gallagher L, Fahey TJ, 3rd. Molecular profiling distinguishes papillary carcinoma from benign thyroid nodules. J Clin Endocrinol Metab. 2004; 89: 3214-23.

81. Yano Y, Uematsu N, Yashiro T, Hara H, Ueno E, Miwa M, et al. Gene expression profiling identifies platelet-derived growth factor as a diagnostic molecular marker for papillary thyroid carcinoma. Clin Cancer Res. 2004; 10: 2035-43

82. Zhao J, Leonard C, Brunner E, Gemsenjager E, Heitz PU, Odermatt B. Molecular characterization of well-differentiated human thyroid carcinomas by cDNA arrays. Int J Oncol. 2006; 29: 1041-51.

83. Fujarewicz K, Jarząb $M$, Eszlinger $M$, Krohn $K$, Paschke R, Oczko-Wojciechowska M, et al. A multi-gene approach to differentiate papillary thyroid carcinoma from benign lesions: Gene selection using support vector machines with bootstrapping. Endocrine-Related Cancer. 2007; 14: 809-26.

84. Murphy KM, Chen F, Clark DP. Identification of immunohistochemical biomarkers for papillary thyroid carcinoma using gene expression profiling. Hum Pathol. 2008; 39: 420-6.

85. Oler G, Camacho CP, Hojaij FC, Michaluart P, Riggins GJ, Cerutti JM. Gene expression profiling of papillary thyroid carcinoma identifies transcripts correlated with BRAF mutational status and lymph node metastasis. Clin Cancer Res. 2008; 14: 4735-42.

86. Kim HS, Kim DH, Kim JY, Jeoung NH, Lee IK, Bong JG, et al. Microarray analysis of papillary thyroid cancers in Korean. Korean J Intern Med. 2010; 25: 399-407.

87. Vierlinger K, Mansfeld MH, Koperek O, Nohammer C, Kaserer K, Leisch F. Identification of SERPINA1 as single marker for papillary thyroid carcinoma through microarray meta analysis and quantification of its discriminatory power in independent validation. BMC Med Genomics. 2011; 4: 30.

88. Chung K-W, Kim SW, Kim SW. Gene expression profiling of papillary thyroid carcinomas in Korean patients by oligonucleotide microarrays. J Korean Surg Soc. 2012; 82: 271-80.

89. Qu T, Li YP, Li XH, Chen Y. Identification of potential biomarkers and drugs for papillary thyroid cancer based on gene expression profile analysis. Mol Med Rep. 2016; 14: 5041-8.

90. Zhang S, Wang Y, Chen M, Sun L, Han J, Elena VK, et al. CXCL12 methylation-mediated epigenetic regulation of gene expression in papillary thyroid carcinoma. Sci Rep. 2017; 7: 44033.

91. Chou C-K, Liu R-T, Kang H-Y. MicroRNA-146b: A novel biomarker and therapeutic target for human papillary thyroid cancer. Int J Mol Sci. 2017; 18: 636

92. Huang Y, Liao D, Pan L, Ye R, Li X, Wang S, et al. Expressions of miRNAs in papillary thyroid carcinoma and their associations with the BRAFV600E mutation. Eur J Endocrinol. 2013; 168: 675-81.

93. Erler P, Keutgen XM, Crowley MJ, Zetoune T, Kundel A, Kleiman D, et al. Dicer expression and microRNA dysregulation associate with aggressive features in thyroid cancer. Surgery. 2014; 156: 1342-50.

94. He H, Jazdzewski K, Li W, Liyanarachchi S, Nagy R, Volinia S, et al. The role of microRNA genes in papillary thyroid carcinoma. Proc Natl Acad Sci U S A. 2005; 102: 19075-80.

95. Pallante P, Visone R, Ferracin M, Ferraro A, Berlingieri MT, Troncone G, et al. MicroRNA deregulation in human thyroid papillary carcinomas. Endocr Relat Cancer. 2006; 13: 497-508.

96. Dong S, Jin M, Li Y, Ren P, Liu J. MiR-137 acts as a tumor suppressor in papillary thyroid carcinoma by targeting CXCL12. Oncol Rep. 2016; 35: 2151-8

97. Minna E, Romeo P, Dugo M, De Cecco L, Todoerti K, Pilotti S, et al. miR-451a is underexpressed and targets AKT/mTOR pathway in papillary thyroid carcinoma. Oncotarget. 2016; 7: 12731-47.

98. Rosignolo F, Memeo L, Monzani F, Colarossi C, Pecce V, Verrienti A, et al. MicroRNA-based molecular classification of papillary thyroid carcinoma. Int J Oncol. 2017; 50: 1767-77.

99. Yu S, Liu Y, Wang J, Guo Z, Zhang Q, Yu F, et al. Circulating microRNA profiles as potential biomarkers for diagnosis of papillary thyroid carcinoma. J Clin Endocrinol Metab. 2012; 97: 2084-92.

100. Lee JC, Zhao JT, Clifton-Bligh RJ, Gill A, Gundara JS, Ip JC, et al. MicroRNA-222 and microRNA-146b are tissue and circulating biomarkers of recurrent papillary thyroid cancer. Cancer. 2013; 119: 4358-65.

101. Cantara S, Pilli T, Sebastiani G, Cevenini G, Busonero G, Cardinale S, et al. Circulating miRNA95 and miRNA190 are sensitive markers for the differential diagnosis of thyroid nodules in a Caucasian population. J Clin Endocrinol Metab. 2014; 99: 4190-8.

102. Li M, Song Q, Li H, Lou Y, Wang L. Circulating miR-25-3p and miR-451a may be potential biomarkers for the diagnosis of papillary thyroid carcinoma. PLoS ONE. 2015; 10: e0132403.

103. Graham ME, Hart RD, Douglas S, Makki FM, Pinto D, Butler AL, et al. Serum microRNA profiling to distinguish papillary thyroid cancer from benign thyroid masses. J Otolaryngol Head Neck Surg. 2015; 44: 33.

104. Yu S, Liu X, Zhang Y, Li J, Chen S, Zheng H, et al. Circulating microRNA124-3p, microRNA9-3p and microRNA196b-5p may be potential signatures for differential diagnosis of thyroid nodules. Oncotarget. 2016; 7: 84165-77.

105. Yoruker EE, Terzioglu D, Teksoz S, Uslu FE, Gezer U, Dalay N. MicroRNA expression profiles in papillary thyroid carcinoma, benign thyroid nodules and healthy controls. J Cancer. 2016; 7: 803-9.

106. Celano M, Rosignolo F, Maggisano V, Pecce V, Iannone M, Russo D, et al. MicroRNAs as biomarkers in thyroid carcinoma. Int J Genomics. 2017; 2017: 11.

107. Pang WW, Abdul-Rahman PS, Wan-Ibrahim WI, Hashim OH. Can the acute-phase reactant proteins be used as cancer biomarkers? Int J Biol Markers. 2010; 25: 1-11

108. Srisomsap C, Subhasitanont P, Otto A, Mueller EC, Punyarit P, Wittmann-Liebold B, et al. Detection of cathepsin B up-regulation in neoplastic thyroid tissues by proteomic analysis. Proteomics. 2002; 2: 706-12.

109. Brown LM, Helmke SM, Hunsucker SW, Netea-Maier RT, Chiang SA, Heinz DE, et al. Quantitative and qualitative differences in protein 
expression between papillary thyroid carcinoma and normal thyroid tissue. Mol Carcinog. 2006; 45: 613-26.

110. Abdullah MI, Lee CC, Mat Junit S, Ng KL, Hashim OH. Tissue and serum samples of patients with papillary thyroid cancer with and without benign background demonstrate different altered expression of proteins. PeerJ. 2016; 4: e2450.

111. Giusti L, Iacconi P, Ciregia F, Giannaccini G, Donatini GL, Basolo F, et al. Fine-needle aspiration of thyroid nodules: Proteomic analysis to identify cancer biomarkers. J Proteome Res. 2008; 7: 4079-88.

112. Sofiadis A, Dinets A, Orre LM, Branca RM, Juhlin CC, Foukakis T, et al. Proteomic study of thyroid tumors reveals frequent up-regulation of the Ca2+ -binding protein S100A6 in papillary thyroid carcinoma. Thyroid. 2010; 20: 1067-76.

113. Martinez-Aguilar J, Clifton-Bligh R, Molloy MP. Proteomics of thyroid tumours provides new insights into their molecular composition and changes associated with malignancy. Sci Rep. 2016; 6: 23660.

114. Fan Y, Shi L, Liu Q, Dong R, Zhang Q, Yang S, et al. Discovery and identification of potential biomarkers of papillary thyroid carcinoma. Mol Cancer. 2009; 8: 79.

115. Jayapalan JJ, Lee C-S, Lee CC, Ng KL, Junit SM, Hashim OH. iTRAQ analysis of urinary proteins: Potential use of gelsolin and osteopontin to distinguish benign thyroid goiter from papillary thyroid carcinoma. Clin Biochem. 2018; 53: 127-31.

116. Torres-Cabala C, Bibbo M, Panizo-Santos A, Barazi H, Krutzsch H, Roberts DD, et al. Proteomic identification of new biomarkers and application in thyroid cytology. Acta Cytol. 2006; 50: 518-28.

117. Jung EJ, Moon HG, Park ST, Cho BI, Lee SM, Jeong CY, et al. Decreased annexin A3 expression correlates with tumor progression in papillary thyroid cancer. Proteomics Clin Appl. 2010; 4: 528-37.

118. Reis CF, Carneiro AP, Vieira CU, Fujimura PT, Morari EC, Silva SJ, et al. An antibody-like peptide that recognizes malignancy among thyroid nodules. Cancer Lett. 2013; 335: 306-13.

119. Min KW, Bang JY, Kim KP, Kim WS, Lee SH, Shanta SR, et al. Imaging mass spectrometry in papillary thyroid carcinoma for the identification and validation of biomarker proteins. J Korean Med Sci. 2014; 29: 934-40.

120. Dinets A, Pernemalm M, Kjellin H, Sviatoha V, Sofiadis A, Juhlin CC, et al. Differential protein expression profiles of cyst fluid from papillary thyroid carcinoma and benign thyroid lesions. PLoS ONE. 2015; 10: e0126472.

121. Zhang H, Yang L, Liu Z, Liu C, Teng X, Zhang L, et al. iTRAQ-coupled 2D LC/MS-MS analysis of CXCR7-transfected papillary thyroid carcinoma cells: A new insight into CXCR7 regulation of papillary thyroid carcinoma progression and identification of potential biomarkers. Oncol Lett. 2017; 14: 3734-40. 